\title{
Drug-related harm among people who inject drugs in Thailand: summary findings from the Mitsampan Community Research Project
}

\author{
Kanna Hayashi ${ }^{1,2}$, Lianping Ti ${ }^{1}$, Nadia Fairbairn ${ }^{1,3}$, Karyn Kaplan ${ }^{4}$, Paisan Suwannawong ${ }^{4}$, Evan Wood ${ }^{1,3}$
} and Thomas Kerr ${ }^{1,3^{*}}$

\begin{abstract}
Background: For decades, Thailand has experienced high rates of illicit drug use and related harms. In response, the Thai government has relied on drug law enforcement to address this problem. Despite these efforts, high rates of drug use persist, and Thailand has been contending with an enduring epidemic of human immunodeficiency virus (HIV) among people who inject drugs (IDU).

Methods: In response to concerns regarding drug-related harm in Thailand and a lack of research focused on the experiences and needs of Thai IDU, the Mitsampan Community Research Project was launched in 2008. The project involved administering surveys capturing a range of behavioral and other data to community-recruited IDU in Bangkok in 2008 and 2009.

Results: In total, 468 IDU in Bangkok were enrolled in the project. Results revealed high rates of midazolam injection, non-fatal overdose and incarceration. Syringe sharing remained widespread among this population, driven primarily by problems with access to syringes and methamphetamine injection. As well, reports of police abuse were common and found to be associated with high-risk behavior. Problems with access to evidence-based drug treatment and HIV prevention programs were also documented. Although compulsory drug detention centers are widely used in Thailand, data suggested that these centers have little impact on drug use behaviors among IDU in Bangkok. Conclusions: The findings from this project highlight many ongoing health and social problems related to illicit drug use and drug policies in Bangkok. They also suggest that the emphasis on criminal justice approaches has resulted in human rights violations at the hands of police, and harms associated with compulsory drug detention and incarceration. Collectively, the findings indicate the urgent need for the implementation of evidence-based policies and programs in this setting.
\end{abstract}

Keywords: Injection drug use, Drug law enforcement, Harm reduction, Community-based participatory research, Thailand

\section{Background}

Thailand has experienced longstanding epidemics of illicit drug use and human immunodeficiency virus (HIV) among people who inject drugs (IDU). During the 1970s, Thailand became the world's largest opium refining and distribution center, and accordingly, heroin use

\footnotetext{
* Correspondence: uhritk@cfenet.ubc.ca

'Urban Health Research Initiative, British Columbia Centre for Excellence in HIV/AIDS, St. Paul's Hospital, 608-1081 Burrard Street, Vancouver, BC V6Z 1Y6, Canada

${ }^{3}$ Faculty of Medicine, University of British Columbia, 317-2194 Health

Sciences Mall, Vancouver, BC V6T 1Z3, Canada

Full list of author information is available at the end of the article
}

quickly became a major driver of drug-related harm in this setting [1,2]. Since the late 1990s, there has been a dramatic increase in the use of methamphetamine in Thailand, which has become the most commonly used illicit drug in the country today [3]. In response, the Thai government has relied on criminal justice approaches in an effort to eradicate illicit drugs. However, the national household survey indicates that illicit drug use remains widespread, with an estimated over $5 \%$ of the population having used illicit drugs in 2007 [4]. The prevalence of HIV among Thai IDU remains strikingly high, with approximately $30-40 \%$ of IDU living with HIV during the

\section{Biomed Central}


past two decades [5]. Although the Thai government offers a range of HIV prevention, care and treatment services for free (e.g., HIV testing and antiretroviral therapy), past reports suggested that IDU faced many barriers to access these services [6].

In response, IDU in Thailand have organized themselves and called for funding to institute evidence-based harm reduction and treatment strategies for them. In 2003, a drug user-driven harm reduction initiative was launched with funding from the Global Fund to Fight to AIDS, Tuberculosis and Malaria (GFATM) [7]. Although this civil society-driven movement led to the inclusion of methadone treatment in the national health security program in 2008 [5], needle and syringe programs (NSPs), which is recommended by the World Health Organization (WHO) and other United Nations (UN) agencies as an essential HIV prevention service for IDU [8], remain controversial: While public health authorities have endorsed NSPs, legal authorities regard it as illegal $[9,10]$. The legal uncertainty has created a challenging environment for some civil society organizations that were allowed to operate NSPs with funding from the GFATM, while their service providers were routinely arrested by police $[6,11]$. To date, the coverage of NSPs remains as low as less than $1 \%$ among Thai IDU [12].

In 2002, Thailand enacted the Narcotic Addict Rehabilitation Act B.E. 2545, which reclassified people who use drugs as "patients" instead of "criminals." Despite this reclassification, in practice, Thailand continues to support large-scale police crackdowns and the expansion of compulsory drug detention centers (CDDCs) [13,14]. Most notably, a "war on drugs" policy in 2003 led to the extrajudicial killings of over 2,800 people and sparked criticism both domestically and internationally $[15,16]$. However, the intensive drug law enforcement-based approach continues to be endorsed by successive Thai governments $[17,18]$, and the impact of this policy approach on the health and behavior of IDU remains unevaluated. As well, little is known about the coverage, quality, and effectiveness of public health programs for IDU in this setting.

In light of persistent concerns regarding drug policy in Thailand, the Mitsampan Community Research Project, an academic-community research partnership involving people who use drugs in Bangkok, was launched in 2008. This report briefly describes the project and summarizes the key peer-reviewed findings from the project.

\section{Mitsampan Community Research Project and research methods}

The Mitsampan Community Research Project is a collaborative research effort involving the Mitsampan Harm Reduction Center (MSHRC; Bangkok, Thailand), Thai AIDS Treatment Action Group (TTAG; Bangkok, Thailand),
Chulalongkorn University (Bangkok, Thailand), and the Urban Health Research Initiative of the British Columbia Centre for Excellence in HIV/AIDS/University of British Columbia (Vancouver, Canada). The MSHRC is a drug user-run drop-in center opened in 2004 with funding from the GFATM. The center provides a range of programs and harm reduction services (e.g., NSPs, health education, counseling and assistance in accessing healthcare), and is also active in advocating for the human rights of people who use drugs. The overarching objectives of this research were to investigate patterns of drug use, health services use, interactions with the criminal justice system, and health-related harms among IDU in Bangkok.

The specific methods employed in this research have been described in detail elsewhere [19]. In brief, it employs a serial cross-sectional study design, and the data used for this report were collected over two cycles of surveying in August 2008 and June - July 2009. The study participants were all active IDU residing in Bangkok or in adjacent provinces and being $\geq 18$ years old when they enrolled in the study. Active IDU were defined as individuals who had injected drugs at least once in the six months prior to the interview. In 2008 and 2009, potential study participants were contacted through peer outreach and word-of-mouth, and were invited to the MSHRC to participate in the study. After providing oral informed consent, participants completed an interviewer-administered questionnaire covering a range of topics including demographics, drug use patterns, HIV risk behavior, health problems, access to healthcare and harm reduction services, and experiences with the criminal justice system. HIV seropositivity was also determined through self-reporting. Since the study's focus on vulnerable populations and collecting data on illegal activities raised ethical concerns, we employed oral consent to protect the participant's anonymity and confidentiality. Additionally, the data collected did not include any identifying information or permit identification of specific individuals. The study was approved by the research ethics boards of Chulalongkorn University and the University of British Columbia.

This report summarizes the results of twelve peerreviewed studies conducted through the Mitsampan Community Research Project. In keeping with the overarching research objectives, four studies were conducted to investigate four different aspects of harms associated with drug use [20-23]. Similarly, four studies examined experiences of four different dimensions of drug law enforcement [24-27], and four studies focused on access to various healthcare and harm reduction services among IDU in Bangkok [28-31]. Because each study addressed a different research question, they employed different participant eligibility criteria, variables, sample sizes, and statistical analyses. The analytical methods have been 
described in detail in each published study. In most of the studies, conventional regression methods (i.e., multivariable logistic regression) were used to address the study objective.

\section{Results: summary of findings IDU recruitment}

In total, 252 IDU participated in the study in August 2008, and 317 IDU participated in the study between June and July 2009. Therefore, an accumulated total of 569 IDU were enrolled in the study over the two years. Because 101 individuals participated in the study in both years, the study reached a total of 468 unique IDU ( 252 individuals in 2008 and 216 individuals in 2009). Sample characteristics are shown in Table 1. As shown, 157 (27.6\%) were women, and the median age was 36 years (interquartile range [IQR]: $32-46$ years). The three most commonly injected drugs by the study participants during the previous six months were: heroin (91.3\%), midazolam (65.9\%), and methamphetamine (57.5\%) in 2008; and midazolam (80.4\%), heroin (65.3\%), and methamphetamine $(65.3 \%)$ in 2009 . The prevalence of selfreported HIV seropositivity was $17.4 \%$ over the two years. Of note, 362 IDU (77.4\%) newly accessed the MSHRC as a result of their participation in the study, and an increase in the attendance rate at the MSHRC has been observed since the launch of the project [19]. The effective involvement of MSHRC members in the study likely facilitated the observed high rates of IDU recruitment [19].

\section{Drug-related harm}

In order to better understand the health status of and risks facing IDU in Bangkok, four studies were conducted to examine the prevalence and correlates of drug-related harm commonly experienced among the study participants. Anecdotal reports suggested that an increasing number of IDU in Bangkok were injecting midazolam-a short-acting benzodiazepine that can be acquired through private clinics. In 2008, over two thirds (67.5\%) of participants in our study reported a history of midazolam injection, and $57.1 \%$ reported daily injection of midazolam in the previous six months. Midazolam injection was independently associated with polysubstance use (adjusted odds ratio $[\mathrm{AOR}]=5.86$; $95 \%$ CI: $2.96-11.60)$ and binge drug use $(\mathrm{AOR}=2.25$; $95 \%$ CI: $1.09-4.63)$, and was commonly used in combination with both opiates and methamphetamine [20].

Our study involving 238 IDU in 2008 demonstrated that $30.3 \%$ of participants reported syringe borrowing in the past six months. Consistent with past research [32,33], syringe borrowing was defined as injecting with a syringe used by others. As shown in Figure 1, syringe borrowing was independently associated with difficulty accessing sterile syringes (adjusted odds ratio $[\mathrm{AOR}]=$ 2.46; 95\% confidence interval [CI]: 1.08-5.60). Primary reasons for experiencing difficulty accessing syringes included being too far from syringe outlets, pharmacies being closed, and being refused syringes at pharmacies [21]. These findings suggest that poor access to sterile syringes is driving the high rate of syringe borrowing

Table 1 Characteristics of a community-recruited sample of IDUs in Bangkok, Thailand, participating in the Mitsampan Community Research Project in 2008 and 2009 ( $n=569)$

\begin{tabular}{|c|c|c|c|}
\hline \multirow[t]{4}{*}{ Characteristic } & \multirow[t]{4}{*}{ Total $n(\%)$} & \multicolumn{2}{|c|}{ Study enrolment } \\
\hline & & 2008 & 2009 \\
\hline & & $252(44.3 \%)$ & $317(55.7 \%)$ \\
\hline & & $n$ (column\%) & $n$ (column\%) \\
\hline Female gender & $157(27.6 \%)$ & $66(26.2 \%)$ & $91(28.7 \%)$ \\
\hline \multicolumn{4}{|l|}{ Age } \\
\hline$<35$ years & $243(42.7 \%)$ & $111(44.0 \%)$ & $132(41.6 \%)$ \\
\hline $35-45$ years & $175(30.8 \%)$ & $74(29.4 \%)$ & $101(31.9 \%)$ \\
\hline$\geq 46$ years & $151(26.5 \%)$ & $67(26.6 \%)$ & $84(26.5 \%)$ \\
\hline \multicolumn{4}{|l|}{ Drugs injected at least once ${ }^{a}$ : } \\
\hline Heroin & $437(76.8 \%)$ & $230(91.3 \%)$ & $207(65.3 \%)$ \\
\hline Methamphetamine & $352(61.9 \%)$ & $145(57.5 \%)$ & $207(65.3 \%)$ \\
\hline Midazolam & $421(74.0 \%)$ & $166(65.9 \%)$ & $255(80.4 \%)$ \\
\hline Self-reported HIV seropositivity & $99(17.4 \%)$ & $29(11.5 \%)$ & $70(22.1 \%)$ \\
\hline Being on antiretroviral therapy ${ }^{\mathrm{b}}$ & $54(54.5 \%)^{c}$ & $21(72.4 \%)^{c}$ & $33(47.1 \%)^{c}$ \\
\hline
\end{tabular}

IDUs: injection drug users.

a Denotes activities during the 6 months prior to the interview.

b Denotes activities at the time of interview.

' The number of HIV-infected individuals is used as a denominator. 




Figure 1 Multivariate logistic regression analysis of factors associated with syringe borrowing among Thai IDU $(n=238)$.

observed in this study, and various lines of evidence corroborate this interpretation $[34,35]$.

Methamphetamine injection appeared to be increasing among IDU in Bangkok, raising concerns about the associated impacts on HIV risk behavior among this population. Among 311 study participants in 2009, 36.7\% reported having injected methamphetamine pills, locally referred to as "yaba," twice or more per week in the previous six months. The prevalence of methamphetamine injection observed in this study was much higher than previously reported rates using data collected during 1999 and 2004 [36,37]. In multivariate logistic regression analyses, after adjustment for potential social, demographic and behavioral confounders, syringe sharing (i.e., borrowing or lending used syringes from or to others) in the past six months remained independently associated with injecting methamphetamine more than once per week $(\mathrm{AOR}=2.86$; 95\% CI: 1.59-5.15) [22].

Although drug-related overdose is a leading cause of death among people who use drugs globally [38-40], the overdose experiences of Thai IDU have not been investigated. Our study conducted in 2008 found that $29.8 \%$ of participants had a history of overdose, and reporting a history of overdose was independently associated with a history of incarceration (AOR $=3.83$; 95\% CI: $1.52-9.65$ ).
The majority of participants (67.9\%) had also responded at the scene of an overdose. While many reported responses with resuscitative potential, almost half reported engaging in responses with low life-saving potential, such as injecting the individual with salt water [23].

\section{Experiences with drug law enforcement}

Given the ongoing emphasis on drug law enforcement in Thailand, we conducted a series of analyses to examine experiences with drug law enforcement among 252 IDU recruited in 2008. The first study exploring incarceration experiences demonstrated high rates of HIV risk behavior among IDU who had been in prison. The majority of participants (78.2\%) reported a history of incarceration, and approximately 30\% reported using drugs while in prison; $81.4 \%$ of these individuals also shared used syringes while incarcerated. A history of imprisonment was independently associated with a history of syringe sharing (AOR $=2.20$; 95\% CI: 1.12 - 4.32) [24].

Our examination of the prevalence and correlates of experiences with CDDCs revealed that $31.7 \%$ of participants had been in a CDDC at some point. As shown in Table 2, the exposure to CDDCs was independently associated with experiencing police abuse (i.e., having illicit drugs planted on oneself by police) $(\mathrm{AOR}=1.81$;

Table 2 Multivariate logistic regression analysis of factors associated with compulsory drug detention exposure among Thai IDU $(n=252)$

\begin{tabular}{|c|c|c|c|}
\hline Variable & Adjusted Odds Ratio (AOR) & 95\% Confidence Interval (Cl) & $p$-value \\
\hline \multicolumn{4}{|l|}{ Ever used drugs in combination } \\
\hline (yes vs. no) & 1.78 & $(0.94-3.36)$ & 0.078 \\
\hline \multicolumn{4}{|l|}{ Ever had drugs planted by police } \\
\hline (yes vs. no) & 1.81 & $(1.04-3.15)$ & 0.035 \\
\hline \multicolumn{4}{|c|}{ Median daily expenses for purchasing drugs } \\
\hline ( $\geq 300$ THB vs. $<300$ THB) & 1.86 & $(1.07-3.22)$ & 0.028 \\
\hline
\end{tabular}

Reproduced from Csete et al. [25]. 
95\% CI: $1.04-3.15)$. Further, the intensity of recent injection drug use did not differ between those who were and were not exposed to CDDCs $(p>0.14)$ [25]. These findings suggest that CDDCs are associated with police abuse and appear not to be helping to reduce drug use among IDU in Bangkok.

Previous studies have shown that intensive drug market policing can produce harmful impacts on public health [41]. In two separate studies, encounters with police were operationalized into two variables: (1) experiences with evidence planting by police (in the form of police placing illicit drugs on an individual) as an indicator of direct encounters with police; and (2) perceiving an increase in police presence where people obtained or used drugs in the previous six months as an indicator of indirect encounters with police. The first study revealed a high rate of police abuse against IDU: $48.4 \%$ of participants reported having illicit drugs planted on them by police. In multivariate analyses, this form of police misconduct was strongly associated with a history of overdose $(\mathrm{AOR}=2.56 ; 95 \% \mathrm{CI}: 1.40-4.66)$, syringe lending $(\mathrm{AOR}=2.08$; 95\% CI: $1.19-3.66)$ and having been in a CDDC $(\mathrm{AOR}=1.88 ; 95 \%$ CI: 1.05 - 3.36). Moreover, among those who reported having drugs planted on them by police, almost half $(48.3 \%)$ paid police a bribe (median $=5,000$ Thai Baht or approximately \$140 USD) in order to avoid arrest [26].

Among the same sample, $54.4 \%$ reported observing an increase in police presence where they obtained or used drugs in the previous six months. However, levels of drug use did not vary among those who did and did not report observing an increase in police presence [27]. Despite the continued use of police crackdowns, the findings suggest that increasing police presence in drug markets appears to have had little effect in reducing drug use among IDU in Bangkok.

\section{Access to health care and harm reduction services}

Four studies have been conducted to examine access to essential health and harm reduction services among IDU in Bangkok. The first study sought to investigate access to methadone treatment, one of the core interventions for HIV prevention and care for IDU [8]. While methadone treatment has been available in Bangkok for decades, concerns have been raised regarding inadequate daily dosing and the provision of methadone as a short detoxification program [42]. To conduct an external assessment of methadone treatment programs in Bangkok, 273 IDU who had a history of heroin or other opiate use were recruited in 2009. In total, $52.4 \%$ opiate users had accessed methadone treatment in the previous six months, but almost all (98.6\%) of them relapsed into active drug use while on treatment. As shown in Figure 2, injecting midazolam twice or more per week was independently associated with being enrolled in methadone treatment $(\mathrm{AOR}=1.85 ; 95 \% \mathrm{CI}: 1.04-3.29)$. High rates of ongoing drug use among methadone patients is likely indicative of the suboptimal system of methadone provision in Bangkok, consistent with previous reports [42]. Moreover, $72.7 \%$ reported having stopped methadone treatment, and the most common reason for stopping methadone was incarceration [28].

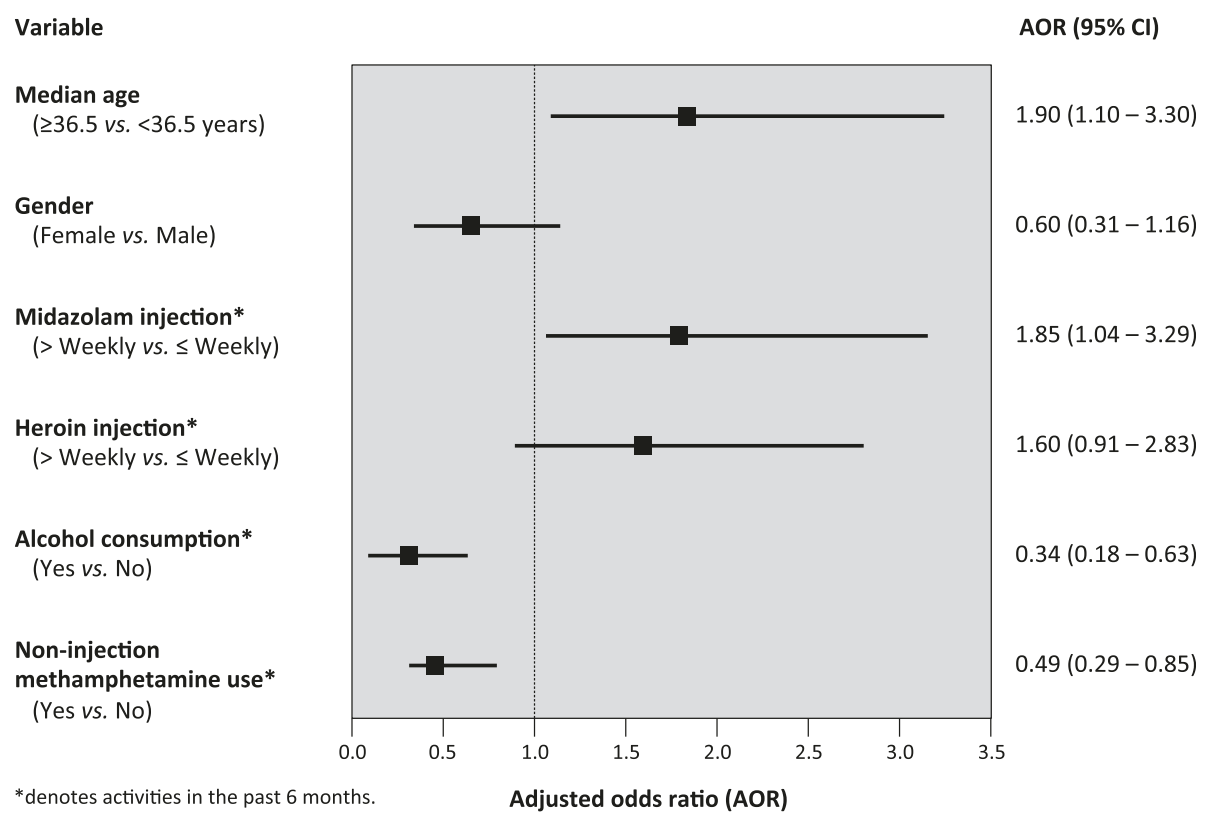

Figure 2 Multivariate logistic regression analysis of factors associated with accessing methadone treatment in the previous 6 months among a community-recruited sample of people who inject drugs in Bangkok, Thailand $(n=273)$. 
The second study described the prevalence of and factors associated with HIV testing behavior and explored the willingness to access rapid HIV testing at the MSHRC among HIV-negative IDU or IDU of unknown HIV serostatus. Although $76.2 \%$ of the study sample received HIV testing in the previous six months, $56.9 \%$ of those who had not been tested in the previous six months reported engaging in HIV risk behavior in the previous six months. Also, it was unclear whether the high rate of testing observed in the study was partially a reflection of the existence of the tenofovir trial (a preexposure prophylaxis trial conducted out of Bangkok Metropolitan Administration methadone clinics) [43], as enrolment in the trial was strongly associated with receiving HIV testing (odds ratio $=44.81$; 95\% CI: $13.44-149.45)$. In total, $74.2 \%$ of participants expressed willingness to receive rapid HIV testing at the MSHRC if it were made available [29].

The third study examined access to testing for hepatitis $\mathrm{C}$ virus (HCV) among IDU who were living with HIV. Although HIV and HCV co-infection is highly prevalent among Thai IDU [44], and WHO recommends that all people living with $\mathrm{HIV}$ be screened for $\mathrm{HCV}$ [45], only half (52.2\%) of the HIV-infected IDU who enrolled in the study had ever been tested for HCV. This appeared to be related to a lack of awareness of HCV, as primary reasons given for not getting tested for $\mathrm{HCV}$ included "never heard of HCV" (65.6\%) and "not aware of HCV risks" (37.5\%). Further, rates of HCV risk behavior (i.e., syringe sharing) were high (38.2\%) among HIVpositive IDU who did not know their HCV status [30]. The deficit in $\mathrm{HCV}$ case finding uncovered in this study is significant, given the high rates of $\mathrm{HCV}$ risk behavior observed among the study sample and the independent contribution of HCV to morbidity and mortality among HIV-infected IDU [46].

Lastly, an evaluation of the MSHRC was conducted by examining factors associated with access to the MSHRC. In 2008, 29.3\% of participants surveyed had accessed the MSHRC, and these individuals were four times more likely to have had difficulty accessing sterile syringes than those who had not previously accessed the MSHRC (AOR = 4.05; 95\% CI: $1.67-$ 9.80). Forms of support most commonly accessed at the MSHRC included sterile syringes (100\%), food and a place to rest $(83.8 \%)$, and information about HIV (75.7\%) and safer injecting (66.2\%) [31]. Consistent with a large body of research indicating the benefits of peer-based approaches in providing public health education and services to IDU [47-50], the results of this study demonstrated that the peer-run MSHRC is helping to expand harm reduction programming in Bangkok by reaching a sub-population of IDU at heightened risk of HIV infection.

\section{Discussion}

The results of the Mitsampan Community Research Project reveal that IDU in Bangkok continue to engage in high rates of HIV risk behavior (i.e., syringe sharing) and suffer from high rates of drug-related harm, including overdose. The findings also indicate a lack of appropriate healthcare service provision and problems with suboptimal service delivery among this population, as low rates of sterile syringe access, HCV testing and awareness, and poor outcomes from methadone treatment persist. A number of social and structural factors appear to be driving these problems, including the limited availability of evidence-based interventions targeting IDU, an overreliance on drug law enforcement and incarceration, and a failure to adhere to international guidelines on HIV prevention and care, and drug treatment for IDU. Although Thailand has continued to rely on intensive drug law enforcement, the evidence derived from this study suggest that this approach is failing to produce reductions in drug use, and is associated with human rights violations and the perpetuation of a system of compulsory drug detention that appears to have little impact on the drug use behaviors of IDU in Bangkok. On the other hand, a promising means to reduce drug-related harm among this population was identified at the drug user-run harm reduction center where IDU experiencing difficulty in accessing sterile syringes obtain sterile syringes and other supports.

Many of our findings are congruent with previous studies identifying various pathways through which intensified drug law enforcement produces harmful impacts on the health of IDU and public health [41,51-54]. For example, in previous studies from other countries, increasing policing in drug markets has been shown to have had no effect in reducing injection drug use [54] but instead have resulted in shifts in local drug use patterns and greater harm [51,55]. Our research also demonstrated that perceived increases in police presence in drug markets did not seem to reduce injecting behavior among IDU in Bangkok [27]. As well, data from this project suggested that midazolam and methamphetamine injection is increasing despite ongoing intensive police crackdowns, and injection of these substances was shown to be associated with risk factors of HIV infection and overdose [20,22]. In particular, the finding that the observed prevalence of methamphetamine injection appeared to be higher than the previously reported rates may reflect the concurrent growth of the methamphetamine market suggested in the government's reports [3], although this explanation warrants a further examination. Further, the observed high rates of police abuse and the strong association with risk taking among IDU in this setting [26] is consistent with previous research indicating that aggressive policing practices not only 
produce direct harm to IDU but also function as pathways to more distal forms of drug-related harm $[41,52,56,57]$.

Our findings also point to the urgent need for the implementation of harm reduction measures within prisons. According to the latest official report, $56.4 \%$ of all incarceration events in Thailand are attributable to drug-related charges [58]. Consistent with previous studies [59-61], our study demonstrated alarmingly high rates of HIV risk behavior among IDU in Bangkok who reported a history of incarceration [24]. Moreover, incarceration was also associated with overdose [23] and was reported to be the most common reason for the discontinuation of methadone treatment [28]. The independent association between overdose and incarceration is consistent with evidence from Western settings indicating that incarceration exacerbates the risk of heroin overdose upon release from prisons as a result of reduced tolerance [62]. These findings suggest that incarceration is contributing to the production of a variety of drugrelated harms in this setting. Given the ongoing high rates of incarceration of Thai IDU, our findings reinforce the recommendations by $\mathrm{WHO}$ and other $\mathrm{UN}$ agencies to implement essential harm reduction programs within prisons, including NSPs [53].

The findings of this research also highlight the need to scale up HIV prevention, care and treatment services targeted for IDU in Bangkok. The HIV prevalence among our study sample (17.4\%) was high and similar to the 2010 Integrated Biological and Behavioral Surveys data showing that the HIV prevalence was $21.3 \%$ (CI: 15.2-26.5) among a sample of 412 IDU in Bangkok [63]. The observed rate of syringe borrowing (30\%) [21] was higher than the rates of syringe sharing among IDU in Bangkok reported by two other studies in 2003-2004 (17\%) [37] and 2009 (14\%) [64], although the potential differences in sample characteristics make the comparison difficult. The finding that frequent methamphetamine injection had an independent relationship with syringe sharing [22] builds on previous studies showing heightened risk of HIV seroconversion among methamphetamine injectors $[36,61]$ and calls for the scale-up of NSPs for this sub-population of IDU. Although the Thai government supports some harm reduction programs, the illegality of NSPs is still debated [10]. Given the demonstrated strengths of the MSHRC in reaching a sub-population of IDU at heightened risk of HIV infection due to difficulty accessing sterile syringes [31] and the fact that the MSHRC, like many other drop-in centers implementing NSPs that are operated by civil society organizations, relies on the GFATM grant [11], such peer-run interventions should be supported and scaled up by the government. Also, given the substantial level of willingness to access rapid HIV testing at the MSHRC among HIV-negative IDU or IDU of unknown HIV serostatus [29], it may worth exploring the expansion of peer-led harm reduction interventions in this setting, such as the provision of HIV testing and counseling by peers.

The work described in this report has limitations, and the limitations of each individual study are described in detail in the published versions of the studies. First, as in any research that is based on surveying methods, our research cannot prove causal relationships. Second, as the study sample was not randomly recruited, our findings may not be generalizable to the IDU populations in Bangkok or other parts of Thailand. Third, the selfreported data may be affected by response biases, including socially desirable reporting and recall bias. Therefore, we may have over- or underestimated the true prevalence of drug use or HIV risk behaviors among IDU in Bangkok. However, we also note that this type of data has been commonly utilized in other studies examining drug use patterns and found to be valid $[65,66]$. Finally, building on the present research findings, future research should further examine observed associations between various health and social problems and injection drug use, including the relationship between midazolam injection and dosages of methadone.

\section{Conclusions}

The findings from this research project highlight many ongoing health and social problems related to illicit drug use among IDU in Bangkok. They indicate a lack of appropriate healthcare and harm reduction service provision to this population, problems which are likely contributing to ongoing HIV risk-taking and other drugrelated harms within this population. These findings also suggest that the emphasis on criminal justice approaches has resulted in human rights violations at the hands of police, and harms associated with compulsory drug detention and incarceration. Collectively, the findings indicate the need for urgent government endorsement, funding and independent evaluation of a comprehensive set of IDU-specific harm reduction and addiction treatment programs in Bangkok.

\section{Competing interests}

The authors declare that they have no competing interests.

\section{Authors' contributions}

$\mathrm{KH}$ drafted the manuscript and incorporated all suggestions from co-authors. All authors made significant contributions to the conception of the analyses, interpretation of the data, and drafting of the manuscript. All authors read and approved the final manuscript.

\section{Acknowledgements}

We would particularly like to thank the staff and volunteers at the Mitsampan Harm Reduction Center for their support. We also thank Dr. Niyada Kiatying-Angsulee, Director of Social Research Institute, Chulalongkorn University, for her assistance with developing this project. We gratefully acknowledge a number of graduate students and staff for their 
assistance with data collection and management: Prempreeda Pramoj $\mathrm{Na}$ Ayutthaya, Amnat Chamchern, Wiwat Chotichatmala, Tricia Collingham, Eric Fu, Deborah Graham, Donlachai Hawangchu, Caitlin Johnston, Prapatsara Kaewkoon, Daniel Miles Kane, Calvin Lai, Puripakorn Pakdirat, Cristy Power, Jiezhi Qi, Jirasak Sripramong, Vipawan Suwannawong, Kamon Uppakaew, Peter Vann, Tanyaporn Wansom, and Ruth Zhang. We also thank Joanne Csete, M-J Milloy, Julio Montaner, and Dan Werb for their invaluable contribution to the development of the manuscripts. Particular thanks go to the participants in the project who were courageous enough to share their experiences with us. The project was originally funded by the Michael Smith Foundation for Health Research. Its knowledge translation activities were supported by the Public Health Program and Global Drug Policy Program of the Open Society Foundations. TK is supported by the Michael Smith Foundation for Health Research. KH is supported by the University of British Columbia Doctoral Fellowship.

\section{Author details}

${ }^{1}$ Urban Health Research Initiative, British Columbia Centre for Excellence in HIV/AIDS, St. Paul's Hospital, 608-1081 Burrard Street, Vancouver, BC V6Z 1Y6, Canada. ${ }^{2}$ Interdisciplinary Studies Graduate Program, University of British Columbia, Green College, Green Commons, Room 153A, 6201 Cecil Green Park Rd, Vancouver, BC V6T 1Z1, Canada. ${ }^{3}$ Faculty of Medicine, University of British Columbia, 317-2194 Health Sciences Mall, Vancouver, BC V6T 1Z3, Canada. ${ }^{4}$ Mitsampan Harm Reduction Center / Thai AIDS Treatment Action Group, 18/89 Vipawadee Rd., soi 40 Chatuchak, Bangkok 10900, Thailand.

Received: 9 July 2012 Accepted: 24 September 2013

Published: 7 October 2013

\section{References}

1. Reid G, Costigan G: Revisiting the hidden epidemic: a situation assessment of drug use in Asia in the context of HIV/AIDS. Fairfield: The Center for Harm Reduction, The Burnet Institute; 2002.

2. McCoy AW, Read CB, Adams LP II: The politics of heroin in Southeast Asia. New York: Harper Colophon Books; 1972.

3. Global SMART Programme: Patterns and trends of amphetamine-type stimulants and other drugs: Asia and the Pacific. Vienna: United Nations Office on Drugs and Crime (UNODC); 2011.

4. Assanangkornchai S, Aramrattana A, Perngparn U, Kanato M, Kanika N, Na Ayudhya AS: Current situation of substance-related problems in Thailand. J Psych Associ Thai 2008, 53(Supplement 1):24S-36S.

5. National AIDS Prevention and Alleviation Committee: UNGASS Country Progress Report Thailand: Reporting Period: January 2008 - December 2009. Bangkok; 2010. http://data.unaids.org/pub/Report/2010/thailand_2010_ country_progress_report_en.pdf.

6. Human Rights Watch, Thai AIDS Treatment Action Group: Deadly Denial: Barriers to HIV/AIDS Treatment for People who use Drugs in Thailand. Vol.19. New York: Human Rights Watch; 2007.

7. Kerr T, Kaplan K, Suwannawong P, Jurgens R, Wood E: The global fund to fight AIDS, tuberculosis and malaria: funding for unpopular public-health programmes. Lancet 2004, 364(9428):11-12.

8. World Health Organization (WHO), United Nations Office on Drugs and Crime (UNODC), The Joint United Nations Programme on HIV/AIDS (UNAIDS): WHO, UNODC, UNAIDS Technical Guide for Countries to set Targets for Universal Access to HIV Prevention, Treatment and Care for Injecting Drug Users. Geneva: World Health Organization; 2009.

9. Woon laew! Sanub Sanun chai kem upakorn cheed tee sa-ad pongkan karn tid chuea HIV so pid kod mai [Promotion of clean syringes and paraphernalia for HIV prevention found breaching the law]. Matichon Online 2011. http://www.matichon.co.th/news_detail.php?newsid= 1313497910\&grpid=03\&catid=\&subcatid.

10. Thailand AIDS Response Progress Report 2012: Reporting Period: 2010-2011; 2012. http://www.unaids.org/en/dataanalysis/knowyourresponse/ countryprogressreports/2012countries/ce_TH_Narrative_Report[1].pdf.

11. Harm Reduction International: In The global state of harm reduction 2012: towards an integrated response. Edited by Stoicescu C. London: Harm Reduction International; 2012.

12. Mathers BM, Degenhardt L, Ali H, Wiessing L, Hickman M, Mattick RP, Myers B, Ambekar A, Strathdee SA: HIV prevention, treatment, and care services for people who inject drugs: a systematic review of global, regional, and national coverage. Lancet 2010, 375(9719):1014-1028.
13. Pearshouse R: Compulsory Drug Treatment in Thailand: Observations on the Narcotic Addict Rehabilitation Act B.E. 2545 (2002). Toronto: Canadian HIV/AIDS Legal Network; 2009.

14. Thomson N: Detention as Treatment: Detention of Methamphetamine Users in Cambodia, Laos, and Thailand. New York: International Harm Reduction Development Program, Open Society Institute; 2010.

15. Human Rights Watch: Not Enough Graves: the war on Drugs, HIV/AIDS, and Violations of Human Rights. Vol. 16. New York: Human Rights Watch; 2004.

16. Harm Reduction International, Human Rights Watch: Thailand's 'war On drugs;; 2008. http://www.hrw.org/news/2008/03/12/thailand-s-war-drugs.

17. Thailand Office of the Narcotics Control Board: Roadmap of Drug Surveillance and Establishment of Sustainable Victory Over Drugs 2006-2008. Bangkok; 2006. http://en.oncb.go.th/document/Roadmap06-08.pdf.

18. Thailand Office of the Narcotics Control Board: National Narcotics Control Policy on Five Fences Strategy: 2009-2010. Bangkok; 2009. http://en.oncb.go. th/document/e1-info-5Fence.html.

19. Hayashi K, Fairbairn N, Suwannawong P, Kaplan K, Wood E, Kerr T: Collective empowerment while creating knowledge: a description of a community-based participatory research project with drug users in Bangkok, Thailand. Subst Use Misuse 2012, 47(5):502-510.

20. Kerr T, Kiatying-Angsule N, Fairbairn N, Hayashi K, Suwannawong P, Kaplan K, Zhang R, Wood E: High rates of midazolam injection among drug users in Bangkok, Thailand. Harm Reduction Journal 2010, 7(1):7.

21. Kerr T, Fairbairn N, Hayashi K, Suwannawong P, Kaplan K, Zhang R, Wood E: Difficulty accessing syringes and syringe borrowing among injection drug users in Bangkok, Thailand. Drug Alcohol Rev 2010, 29(2):157-161.

22. Hayashi K, Wood E, Suwannawong P, Kaplan K, Qi J, Kerr T: Methamphetamine injection and syringe sharing among a communityrecruited sample of injection drug users in Bangkok, Thailand. Drug Alcohol Depend 2011, 115(1-2):145-149.

23. Milloy MJ, Fairbairn N, Hayashi K, Suwannawong P, Kaplan K, Wood E, Kerr T: Overdose experiences among injection drug users in Bangkok, Thailand. Harm Reduction J 2010, 7:9.

24. Hayashi K, Milloy MJ, Fairbairn N, Kaplan K, Lai C, Wood E, Kerr T: Incarceration experiences among a community-recruited sample of injection drug users in Bangkok, Thailand. BMC Public Health 2009, 9(1):492.

25. Csete J, Kaplan K, Hayashi K, Fairbairn N, Suwannawong P, Zhang R, Wood E, Kerr T: Compulsory drug detention center experiences among a community-based sample of injection drug users in Bangkok, Thailand. BMC Int Health Human Rights 2011, 11(1):12.

26. Fairbairn N, Kaplan K, Hayashi K, Suwannawong P, Lai C, Wood E, Kerr T: Reports of evidence planting by police among a community-based sample of injection drug users in Bangkok, Thailand. BMC Int Health Human Rights 2009, 9:24.

27. Werb D, Hayashi K, Fairbairn N, Kaplan K, Suwannawong P, Lai C, Kerr T: Drug use patterns among Thai illicit drug injectors amidst increased police presence. Subst Abuse Treat Prev Policy 2009, 4:16.

28. Fairbairn N, Hayashi K, Kaplan K, Suwannawong P, Qi J, Wood E, Kerr T: Factors associated with methadone treatment among injection drug users in Bangkok, Thailand. J Subst Abuse Treat 2012, 43(1):108-113.

29. Ti L, Hayashi K, Kaplan K, Suwannawong P, Fu E, Wood E, Kerr T: HIV testing and willingness to get HIV testing at a peer-run drop-in centre for people who inject drugs in Bangkok, Thailand. BMC Public Health 2012, 12(1):189.

30. Hayashi K, Montaner J, Kaplan K, Suwannawong P, Wood E, Qi J, Kerr T: Low uptake of hepatitis $C$ testing and high prevalence of risk behavior among HIV-positive injection drug users in Bangkok, Thailand. J Acquir Immune Defic Syndr 2011, 56(5):e133-e135.

31. Kerr T, Hayashi K, Fairbairn N, Kaplan K, Suwannawong P, Zhang R, Wood E: Expanding the reach of harm reduction in Thailand: experiences with a drug user-run drop-in centre. Int J Drug Policy 2010, 21(3):255-258.

32. Marshall BD, Wood E, Li K, Kerr T: Elevated syringe borrowing among men who have sex with men: a prospective study. J Acquir Immune Defic Syndr 2007, 46(2):248-252.

33. Pollini RA, Brouwer KC, Lozada RM, Ramos R, Cruz MF, Magis-Rodriguez C, Case P, Burris S, Pu M, Frost SD, et al: Syringe possession arrests are associated with receptive syringe sharing in two Mexico-US border cities. Addiction 2008, 103(1):101-108.

34. Perngmark $\mathrm{P}$, Celentano DD, Kawichai S: Needle sharing among southern Thai drug injectors. Addiction 2003, 98(8):1153-1161. 
35. Perngmark P, Vanichseni S, Celentano DD: The Thai HIV/AIDS epidemic at 15 years: sustained needle sharing among southern Thai drug injectors. Drug Alcohol Depend 2008, 92(1-3):183-190.

36. Martin M, Vanichseni S, Suntharasamai P, Mock PA, Van Griensven F, Pitisuttithum P, Tappero JW, Chiamwongpaet S, Sangkum U, Kitayaporn D, et al: Drug use and the risk of HIV infection amongst injection drug users participating in an HIV vaccine trial in Bangkok, 1999-2003. Int J Drug Policy 2010, 21(4):296-301.

37. Wattana W, Van Griensven F, Rhucharoenpornpanich O, Manopaiboon C, Thienkrua W, Bannatham R, Fox K, Mock PA, Tappero JW, Levine WC: Respondent-driven sampling to assess characteristics and estimate the number of injection drug users in Bangkok, Thailand. Drug Alcohol Depend 2007, 90(2-3):228-233.

38. Hulse GK, English DR, Milne E, Holman CD: The quantification of mortality resulting from the regular use of illicit opiates. Addiction 1999, 94(2):221-229.

39. Stoove MA, Dietze PM, Aitken CK, Jolley D: Mortality among injecting drug users in Melbourne: a 16-year follow-up of the Victorian Injecting Cohort Study (VICS). Drug Alcohol Depend 2008, 96(3):281-285.

40. Degenhardt L, Bucello C, Mathers B, Briegleb C, Ali H, Hickman M, McLaren $\mathrm{J}$ : Mortality among regular or dependent users of heroin and other opioids: a systematic review and meta-analysis of cohort studies. Addiction 2011, 106(1):32-51.

41. Kerr T, Small W, Wood E: The public health and social impacts of drug market enforcement: a review of the evidence. Int J Drug Policy 2005, 16(4):210-220

42. Tyndall M: Harm reduction policies and interventions for injection drug users in Thailand. Bangkok: World Bank; 2011.

43. Martin M, Vanichseni S, Suntharasamai P, Sangkum U, Chuachoowong R, Mock PA, Leethochawalit M, Chiamwongpaet S, Kittimunkong S, Van Griensven F, et al: Enrollment characteristics and risk behaviors of injection drug users participating in the Bangkok Tenofovir Study, Thailand. PLoS One 2011, 6(9):e25127.

44. Walsh N, Verster A, Doupe A, Vitoria M, Lo Y-R, Wiersma S: 3.1. The silent epidemic: responding to viral hepatitis among people who inject drugs In Global State of Harm Reduction 2010: Key Issues for Broadening the Response. Edited by Cook C. London: International Harm Reduction Association; 2010.

45. World Health Organization Regional Office for Europe (WHO-EURO): 6. Management of hepatitis C and HIV coinfection. In HIV/AIDS Treatment and Care: Clinical Protocols for the WHO European Region. Edited by Eramova I, Matic S, Munz M. Copenhagen: WHO-EURO; 2007

46. Sulkowski MS, Thomas DL: Hepatitis C in the HIV-infected person. Ann Intern Med 2003, 138(3):197-207.

47. Broadhead RS, Heckathorn DD, Weakliem DL, Anthony DL, Madray H, Mills RJ, Hughes J: Harnessing peer networks as an instrument for AIDS prevention: results from a peer-driven intervention. Public Health Rep 1998, 113(Suppl 1):42-57.

48. Grund JP, Blanken P, Adriaans NF, Kaplan CD, Barendregt C, Meeuwsen M: Reaching the unreached: targeting hidden IDU populations with clean needles via known user groups. J Psychoactive Drugs 1992, 24(1):41-47.

49. Latkin CA: Outreach in natural settings: the use of peer leaders for HIV prevention among injecting drug users' networks. Public Health Rep 1998, 113(Suppl 1):151-159.

50. Needle RH, Burrows D, Friedman SR, Dorabjee J, TouzÈ G, Badrieva L, Grund J-PC, Kumar MS, Nigro L, Manning G, Latkin C: Effectiveness of communitybased outreach in preventing HIV/AIDS among injecting drug users. I J Drug Policy 2005, 16(Supplement 1):45-57.

51. Maher L, Dixon D: Policing and public health: law enforcement and harm minimization in a street-level drug market. Br J Criminol 1999, 39(4):488-512.

52. Burris S, Blankenship KM, Donoghoe M, Sherman S, Vernick JS, Case P, Lazzarini Z, Koester S: Addressing the "risk environment" for injection drug users: the mysterious case of the missing cop. Milbank Q 2004, 82(1):125-156.

53. Jurgens R: Effectiveness of Interventions to Address HIV in Prisons. Geneva: World Health Organization (WHO), United Nations Office on Drugs and Crime (UNODC), and Joint United Nations Programme on HIV/AIDS (UNAIDS); 2007.

54. Friedman SR, Cooper HL, Tempalski B, Keem M, Friedman R, Flom PL, Des Jarlais DC: Relationships of deterrence and law enforcement to drug- related harms among drug injectors in US metropolitan areas. AIDS 2006, 20(1):93-99.

55. Maher L, Li J, Jalaludin B, Wand H, Jayasuriya R, Dixon D, Kaldor JM: Impact of a reduction in heroin availability on patterns of drug use, risk behaviour and incidence of hepatitis $C$ virus infection in injecting drug users in New South Wales, Australia. Drug Alcohol Depend 2007, 89(2-3):244-250

56. Small W, Kerr T, Charette J, Schechter MT, Spittal PM: Impacts of intensified police activity on injection drug users: evidence from an ethnographic investigation. Int J Drug Policy 2006, 17(2):85-95.

57. Sarang A, Rhodes T, Sheon N, Page K: Policing drug users in Russia: risk, fear, and structural violence. Subst Use Misuse 2010, 45(6):813-864.

58. Department of Corrections, Ministry of Justice, Thailand: Number of Convicted Prisoners by Type of Offences. http://www.correct.go.th/eng/ number_by_type_of_offences.html.

59. Beyrer C, Jittiwutikarn J, Teokul W, Razak MH, Suriyanon V, Srirak N, Vongchuk T, Tovanabutra S, Sripaipan T, Celentano DD: Drug use, increasing incarceration rates, and prison-associated HIV risks in Thailand. AlDS Behav 2003, 7(2):153-161.

60. Choopanya K, Des Jarlais DC, Vanichseni S, Kitayaporn D, Mock PA, Raktham S, Hireanras K, Heyward WL, Sujarita S, Mastro TD: Incarceration and risk for HIV infection among injection drug users in Bangkok. J Acquir Immune Defic Syndr 2002, 29(1):86-94.

61. Buavirat A, Page-Shafer K, Van Griensven GJP, Mandel JS, Evans J, Chuaratanaphong J, Chiamwongpat S, Sacks R, Moss A: Risk of prevalent HIV infection associated with incarceration among injecting drug users in Bangkok, Thailand: case-control study. Br Med J 2003, 326(7384):308.

62. Darke S, Hall W: Heroin overdose: research and evidence-based intervention. J Urban Health 2003, 80(2):189-200.

63. Punsuwan N, Namwat C, Tanpradech S, Pratheepkaew N, Yodreaun K, Jarupan S: Correlates of HIV infection among injection drug users in Bangkok Metropolitan Regions, Chiangmai and Songkhla, Thailand [abstract]. In The 10th International Congress on AIDS in Asia and the Pacific: 26-30 Augusut 2011. Busan, Korea: SuPA042:209.

64. Barrett ME, Perngparn U: Rapid Assessment and Response: Preparation for the Scale-up of Comprehensive Harm Reduction Services in Thailand: Bangkok Province. Bangkok: Asian Harm Reduction Network \& Public Health Sciences College, Chulalongkorn University; 2010.

65. Weatherby NL, Needle R, Cesari H, Booth R, McCoy CB, Watters JK, Williams $M$, Chitwood DD: Validity of self-reported drug use among injection drug users and crack cocaine users recruited through street outreach. Eval Program Plann 1994, 17(4):347-355.

66. Darke S: Self-report among injecting drug users: a review. Drug Alcohol Depend 1998, 51(3):253-263. discussion 267-258.

doi:10.1186/1477-7517-10-21

Cite this article as: Hayashi et al:: Drug-related harm among people who inject drugs in Thailand: summary findings from the Mitsampan Community Research Project. Harm Reduction Journal 2013 10:21.

\section{Submit your next manuscript to BioMed Central and take full advantage of:}

- Convenient online submission

- Thorough peer review

- No space constraints or color figure charges

- Immediate publication on acceptance

- Inclusion in PubMed, CAS, Scopus and Google Scholar

- Research which is freely available for redistribution 